\title{
Status of business model and electronic market research - an interview with Paul Timmers
}

\author{
Rainer Alt, Leipzig University, rainer.alt@uni-leipzig.de \\ Hans-Dieter Zimmermann, FHS St. Gallen, hansdieter.zimmermann@fhsg.ch
}

Published in: Electronic Markets 24(2014)4, pp. 235-241. DOI 10.1007/s12525-014-0177-3

\begin{abstract}
This interview with Paul Timmers reflects on how the domain of business models has emerged since the publication of the first business model article in Electronic Markets in 1998. The interview provides insights in how his seminal article on business models for electronic markets originated and on the role of government bodies, in particular the European Commission. Among the opinions shared are that electronic markets should be conceived as a broad concept and that interdisciplinary views are key for shaping future developments, especially in the area of ubiquitous data in many industries.
\end{abstract}

\section{Background information on Paul Timmers}

Paul Timmers is Director of Sustainable \& Secure Society in the European Commission Directorate General CONNECT since 2012. There he is addressing policy and research for ICT and health, ageing, public services, smart cities as well as cyber security. Since 1996, Paul Timmers has been leading activities in the European Commission in the areas of electronic commerce, e-government, digital inclusion and active \& healthy ageing. As a member of the Cabinet of European Commissioner Erkki Liikanen he was responsible for the information society and telecommunications policy portfolios. Before joining the European Commission he worked in the IT sector and co-founded a software startup. Paul holds a Ph.D. in theoretical physics from the University of Nijmegen, an MBA from Warwick 
Business School, and has been an EU Research Fellow at UNC Chapel Hill, USA. He has widely published and lectured in the field of technology, business and policy.

During the Internet Hype in the second half of the 1990's Paul Timmers was head of the sector Electronic Commerce at the European Commission, Directorate General Information Society. Among others, he was working on the first policy on electronic commerce in the European Commission at that time. As there was hardly an existing body of literature available he started to author several pieces in the area of electronic commerce as well as business models himself based on his experiences in research and innovation management. In 1998 Paul Timmers published his work in the second issue of Electronic Markets, volume 8 (Timmers 1998). His article "Business Models for Electronic Markets" was one of the first scholarly articles at all which addressed the term "business model" and kicked off an intense and vivid discussion in the scholarly as well as in the practitioners' literature. Still today, articles discussing business models refer to this seminal article published in 1998. As a result, Paul Timmers' article has become by far the most cited article of Electronic Markets since its inception.

In the interview, Paul Timmers looks back at the time when he authored the article from today's perspective.

\section{The interview}

Held on May 22, 2014.

Electronic Markets (EM): What is your job in the Commission today and what topics are you working on?

Paul Timmers (PT): I am here a director in the European Commission in the part, which is responsible for the digital agenda. Our Directorate General is called DG Connect and my directorate is called Sustainable and Secure Society. I am responsible for most of the areas where digital is relevant for society, or economic use, or the combination of that. The main areas are ICT and health, ICT and aging, ICT and the public services - or e-government - ICT and the areas of transport, energy, water waste you might say smart cities and also cyber security. The kind of work that is happening here and that falls 
under my responsibility nowadays is the true combination of policy, and the support for research and innovation. So in all of these areas we are doing policy development and sometimes also law development. In the field of security, for example, we are negotiating at this moment a European directive for network and information security. We are also initiating a substantial investment in research and innovation, mostly in the Horizon 2020 program, but also deployment work. There is another program that is actually running services $24 \mathrm{~h} \times 7$, called Connecting Europe Facility at the end. The public services part of that is under my responsibility. That is my portfolio, which is supported by a 180 people working in the directorate.

EM: Do you still remember what you did 16 years back when you wrote the article?

PT: At the time when I also wrote that article, I was fortunate because I was one of the first people who got into the area of electronic commerce. At that time, mostly looking at it from a research and innovation perspective. We were looking carefully at what was happening of course in the United States because there the Internet was coming up. This was 95-96. I got involved in writing down the first policy on electronic commerce in the European Commission, of course with a number of colleagues and I got a lot of information. That is one of the privileges here, that you get a lot of information of what is happening all across Europe and all across the world. I noted that many people were talking about how the Inter- net would be changing business, and they started talking, of course, about business models. Actually no one really had defined what business models were about. As my background is kind of a mix - I have a background of theoretical physics and an MBA — you tend to think more quickly in terms of models, like you probably also do. I said, "OK, can we give some form of a definition that at least gives an idea of what we are talking about?" And secondly, is it possible to do some form of classification of all these business models that were coming up? I must say, honestly say that was just kind of like a lucky strike because that was the right moment in time to do something and to write that paper - and later, as a follow-up of my MBA, to write a book about electronic commerce and electronic business, which describes more about business models.

EM: The motivation to write this article was linked with your master's thesis? 
PT: Yes. It was actually nicely in the middle between working on an MBA and being involved in policy development around electronic commerce at that time. So because if you do policy development, and also if you define work in the fourth framework research program, which we were doing at that time, you need to have an idea of what you are talking about. You are getting numerous opinions, examples, projects and concepts that we then discussed with people at a European level. It was more like an effort of listening carefully and integrating what I heard, and then trying to conceptualize that into this work around business models. But it fitted very nicely also with me completing my master's thesis in business administration. That was not specific IT. Because I do have a fairly strong IT background because I'd been running my own IT company before I joined the European Commission. Before I actually joined, I worked also a while in Philips, and I was an IT department manager there.

EM: Your article published in Electronic Markets was one of the very first addressing business models. What do you think, why has the topic not been addressed before? At least, every company has to have a business model.

PT: Yes, as you know, the journal has close connection to the Bled eConference, and at one moment at the conference in Bled, I met someone who said," You really need to read that book of Karl Weick about sense making." When reading that book, I thought, "Ah. This is an example of sense making because you see a number of signals, then you give words to them, and then people say, Aha, Is this what we were talking about? And how come that we didn't see it before?" So I think it had a lot to do with sense making at that moment in time, from the sense making studies that phenomena which existed already since a long time are then suddenly, getting a word, getting a concept, getting recognized. And people say, “Oh, but I know. This is what I've seen happening since a while." I think that this is probably the normal development of concepts, perhaps science. Of course, you have to take into account that much of the article and certainly also of the book that I wrote on business models, was influenced by marketing theory, for example Kotler who actually describes, without necessarily naming them, business models quite often. 
EM: You mentioned the aspect of science. One important aspect of science is that it evolves. Now 16 years after the article has been published, how do you judge the paper from today's perspective? Is there anything you would do different?

PT: I have thought a little about this question. If you look at these 15-16 years since, many papers were published around business models and much scientific work has also been done.

So the field has definitely become much richer. Some of the key concepts already existed, such as the centrality of value and of relationships, the notion of architecture and the difference between business strategy and business models. Those kind of ideas were described in the beginning of my definition but also in work that others did, and they were elaborated on in subsequent scientific work. But if I look back at the main missing elements, I would definitely say that there is a very important area that was not described at the time, which is the real context in which the business models and businesses operate. Perhaps that is also my bias, because I see so much happening at the regulatory side. You see business models being conditioned, but also influencing the environment around them in terms of policy and regulation, and also in terms of, let's say, social interactions and behavior that changes. So our behavior, our culture, they are also intimately related to business. We did not describe that at that time and these are real areas of research. I was just this morning reading a report about smart grids and how distribution system operators in the smart grids business - they are the ones that are delivering electricity to the regional or to the consumer level - how their business models are going to change because of the emergence of smart meters, big data etc., and which rules that they should play. These are regulated industries, so we already have a certain perception of how they should act in the public interest, but they are massively being challenged because of the change in technology, and therefore their business model has to be reconsidered. You cannot do that in isolation from the existing regulatory environment level alone, from how people will perceive it. Now this is also about data, so actually this operator may know which movie you are watching because of the electricity consumption. So it has become, I think, only more interesting from a scientific point of view.

EM: When you look back these 15 or 16 years, what, from your perspective, are the most successful business models you have heard about? 
PT: I think that quite a number of the transaction-based business models have become successful. At the time, we were describing things like third-party marketplaces. Now there are often not anymore thirdparty marketplaces, but it is the whole marketplace idea, the transaction and the mediation, that has actually become quite successful. In many cases, there is not a third party, but it has been reincorporated into the incumbents that were there and that also saw a change happening and created this kind of marketplaces. They are very successful and we can also trace back what is happening today to the roots 15 to 20 years ago. However, I think the predictive power of business models research is not that large or not that big that you can kind of map out all of the potential business models that might be there and actually identify their potential success. It would be great, of course, if you can do that and people will be doing something else probably. Take the social networks, which have become very successful and important business models, but have not really been predicted by business models theory.

EM: How important is this high-level classification in the business, from your observation?

PT: Actually, I think it is very much educational. You may still wonder whether we get the dimensions right when you do classification. So surely it is useful and we are also using it here inside the European Commission, for example, to make distinctions between various types of business models, and therefore what kind of policy is applicable to it. However, these are always only on a few dimensions, and I think the classifications fail to capture everything that you can learn around a business model. So I would say useful, educationally good, they help you to discover some important dimensions, but then definitely you have to move on and not get stuck in classification work.

EM: What do you think are the basic enablers, risks and challenges of electronic markets back then and maybe today?

PT: What I have seen over the past years coming, for example for the Electronic Markets journal, is that people have apparently difficulty to precisely place their articles relative to the concept of electronic markets. You get quite a wide variety of articles, which are not always strictly related to something like a core of electronic markets. This is kind of weird but for me I must say in itself suggests whether the name Electronic Markets still holds, and whether you should find another name that allows for this wider scope of articles to come in. It is also important because business models were strongly related to 
economic theory, which in turn is moving ahead. For example, you see more coming in around behavioural aspects, which are intimately related to what is happening in electronic markets the moment that they become more data rich. Of course, behavioral economics in itself are closely related to marketing theory and marketing practices. Thus, it is a very important opening up of the perhaps more, originally more transaction-oriented, good old ICT oriented type notion of electronic markets. This is justified because you have to see these kind of concepts in relationship to theory development, such as in economics. Likewise, as I said before, electronic markets are also not living in isolation. They are influenced by, for example, regulation and we are still missing good theory that connects regulation to the phenomenon of electronic markets. Of course, we have the theory around regulation connecting to economics, but it is still missing how you can tune business models given a certain regulatory environment. I did myself, for example, a study when I was for a while in the US into business models that were developed in a certain area regarding how they would be influenced by legislation in the field of health. In my view, you could clearly see from this study that we are missing how regulation precisely interacts or pushes certain business models. There is much speculation, for example, around regulation limiting innovation. But it might also be that regulation raises awareness, which is the starting point of much innovation. Likewise, regulation and electronic markets are often tightly coupled. The other thing, the word "market" also suggests a limitation or a delimitation that should not be there. Many of the business model discussions today are actually about the interplay between public and private, which is highly significant for all of us, and certainly also the European scene. So business model innovation is something that has now entered into the field of social innovation, it is entering into the public sector per se, it is entering into semi-public sector areas, complex areas like health or, as I said before, energy. These are all really important areas to study. As far as I am concerned, if people take electronic markets in a very wide sense, I would be very happy about that.

EM: Although you mentioned the fields of health and energy repeatedly, you did not say anything about the financial industry. What is your opinion on the electronic markets in the financial industry? We have learned that they may cause a large amount of risk.

PT: Yes, but actually you are asking me here beyond my confidence. I do not really know enough about the financial markets, although I should know because my son is working in that area. But in my daily 
work I am not that much involved in the developments around, for example, electronic payment systems, or risk management, or bitcoin type of developments that I could actually say much about it.

EM: What were the most important standards that you have seen emerging in the electronic markets that you have studied, maybe in health or energy?

PT: Well, in energy we see a whole range of standards emerging, which even have to do with the definitions of the system or the system components. For us it is important that these definitions are, let's say, worldwide. We have intensively worked with the Americans, for example, on smart grids terminology standardization. In the field of health, there is significant interest from the European level to enable cross border health provision. Also based upon the number of court cases, a directive has been introduced for that. That means you need to standardize or create interoperability on the exchange, for example, patient data and definitions of medical terms such as those for medications. There is again a whole terminology called Snomed (health terminology) that has been introduced in that area. It is domain-specific and if I generalize from both, the interoperability related to that standardization is a highly strategic area. Despite the fact that there is much public sector interest, it is driven by the private sector. Large consortia have emerged that are in fact defining the standards.

In many cases, these consortia are Trans-Atlantic, if not worldwide. Now I am still more referring to technical standardization. What you see happening now and that is perhaps related to your earlier question about the financial markets, in the field of cyber security, and I am sure it will also spill over into the other areas; we are working on standardization on risk management.

That deals with being able to describe the procedures and processes for, let's say, proportionate adequate risk management in the case of cyber incidents. It also concerns the fact that, by defining those terminologies, actually you are creating a stable basis for a series of business models to be created in cyber insurance. The insurance market is looking keenly at what is happening in terms of standardization, because they are seeking economies of scale and they will want to know that, relative to standardized risk-management procedures, they can see what the levels of risks are and therefore the financial involvement. Now as I say, this is likely to also affect areas like energy, transport, smart cities, and also health, which are lagging a little behind, for example, the financial world in terms of cyber 
security management. The involvement in standards and the relevance of standards is really playing out at all the levels, from the technical, the organizational and the semantic. Some people are even talking about legal interoperability, which to some extent you can make an argument for, if we are talking about, for example, trans-Atlantic data flows.

EM: Many other recent developments or buzzwords are influencing the electronic markets' world. For example, cloud, social and mobile computing, but also the app economy or big data. What do you think are the implications of these developments?

PT: First of all, this kind of new technology developments or enablement by new technology, is now more recognized than before and it generates opportunities for business model innovation. We have, for example, even had a dedicated action at the European level now, after 15 years in the Horizon 2020 research program, which is called Business Model Innovation. We are talking with the advisory group associated to that part of Horizon 2020 about future research that should be done around business model innovation, for example. They are definitely pointing to new technological developments, take 3D printing. There has been much technology development, and we are sure that there is still more coming. While we might have done mostly technology road mapping in the past, we are now increasingly also asking, "So what is kind of the business model road mapping?" This is again where the work that people have been doing around the business models can come in very well. You can also see frequent references to business models in proposals that we are receiving. So I think it is a fertile ground for those that are pursuing business models research to continue providing analytical frameworks that help people to assess how technological developments may play a role. That can be these kind of new technologies, although cloud and social networks are of course not that new. But what is going to be, for example, the impact of powerful data analytics on business models? Again, the tendency that I see is that people really take a wide interpretation of business models. They are also quite willing to likewise consider how relationships which are influencing business models, and how relationships might change, take an example, between citizen and the state. How will powerful data analytics change the participation of citizens in public services design? These are areas that are supported by research and innovation but that I also see happening in practice. Now a little digression on that: Of course electronic commerce, doing business electronically, is much more widespread. That also means that many of the businesses can be 
operating across borders, and they will increasingly use technologies to establish relationships with all kind of countries. If you come from Europe, also the neighboring countries or countries in other parts of the world, this is where you also see clearly that these technologies could play a role and you can build new business relationships around them. But you will be running into the issues of, for example, perception of their power relationships or, what I just said, their relationship between citizen and the state, just as with the historic way that people do business in a country. We are having serious discussions that these studies are also extended by involving, for example, historians, sociologists, cultural anthropologists, ethicists, and obviously the ethical sciences. This is what I mean by a more integrated view on business innovation.

EM: What beyond initiating research and recognition, are activities you see within the European Commission? Did we miss some of your areas?

PT: Much work, and historically of course most of the work of the European Commission - also in my directorate - is rather around legislation, around law making and policy definitions. For example, we recently managed to get adopted a piece of legislation around the use of electronic identification and electronic signatures in Europe, which essentially makes it possible to have legal recognition of electronic identification coming from the national level. That again is a very practical news because it means that people can do business or transfer information across borders, while identifying themselves with the electronic identification system that they have from the national level, and it will be legally recognized. In parallel, we have been supporting the validation that it also works technically. As a consequence, you can, for example, travel to another country, identify yourself as a patient and obtain access to your patient record across borders. If you fall ill in Austria as a Belgian, you produce your Belgium ID and your Austrian doctor would use the Austrian electronic ID. Jointly they can access the patient record and provide an electronic prescription. The same applies to an electronic procurement across borders. If you submit a contract as a company, you can sign and use your electronic signature coming from your trust service provider. It will be legally recognized across borders and will be used massively in electronic procurement. The legal development is necessary, because otherwise you fail to know the legal value of the electronic identification. The technical development is of course necessary to make things interoperable and make it actually work. Most developments were supported by the 
European Commission and they are actually coming out of very long-term activities that are almost as old as business model work around e-government and the like. The political setting around it is that ministers at some moment have agreed that we should realize e-government across borders, because it will bring efficiency and enable people to travel easier across Europe. This is political and legal work as well as support for research and innovation and technical deployment. That is an illustration of the kind of work that the European Commission can do, and I think it is a real illustration of making the single market work in a digital way.

EM: What would be your wish list for academic research in the domain of electronic markets and business models? What kind of research should be done and published in the future?

PT: Big things that we have on our agenda are certainly around data, social networks, the mixed modality business models, so between public and private, which might be applicable to sectors like energy or health. This includes business models that are inspired by new emerging technologies, but also these complex problems of where business models are operating under condition of regulation, under condition of cultural type of behavior. Where are they conditioned by factors that are outside the business model, the firm or the value chain? Again, we lack sufficient models and we even as policymakers need models that can tell us how the interplay of these factors works out at the business level.

EM: You have mentioned several disciplines necessary in this field. Do you think that we need more research combining different disciplines?

PT: This actually is the direction for Horizon 2020. The European research programs are really set up to support more multidisciplinary or interdisciplinary research. This is challenging from the academic point of view, because not everybody is into that type of research. They need to see the opportunities and that these will be larger than what they might lose by not staying purely within their own discipline. From an academic point of view there are also new disciplines that will be emerging and I am happy to see that we are starting to get more people that have a solid IT background and a solid legal background or political science background. What was rare 10 years ago, we now observe more and more of these people coming in. I think it relates not only to academic research itself but also to the academic educational area. I love to have people here who did behavioral economics, understand IT very well, 
and who I can put in a team with a number of lawyers and they understand how law works. This is the kind of combination needed and if people with an ethical or psychology background join these teams, they are most welcome.

EM: Critics say that the type of work that is being published in academic journals is only little relevant for practitioners. What is your opinion on that?

PT: Let me put it that way: It's not black and white. It is not so that practitioners would not read academic papers and would not know what to do with them. At the same time, it is absolutely true that you can push the boundary further to connect practitioners to the academic world. Two illustrations of that, which are again coming from my current work. A few years ago, we have started the idea of European innovation partnerships (EIPs), which are very large gatherings of stakeholders. In principle, they are driven from the demand side. There is one EIP on healthy aging, which is driven from the ones providing health services for elderly people. The same applies for smart cities, which are driven from the city managers. They bring into these partnerships industry and academics, authorities, often also capitalventure capital for example — and sometimes even individual citizens. Those are places where you can actually experiment with applying academic theory, explaining the academic papers to practitioners, and listening to the practitioners to pick up again what you can do in the academic world. Living labs are example places to do that and serious academic work has come out of that. In the field of healthy aging there is a particular challenge to show that innovation actually contributes really to better health. There is a political target to increase by two the number of healthy life years in 2020 , but at a much more practical level people will bring integrated care, medication compliance, full prevention. These are all areas where abundant data is coming in and new operators are fulfilling a role. They will have to show that the innovations have a real impact on micro-level practice life and the quality of life of an individual citizen as well as on (basal) level type of indicators like the number of jobs or the cost of the health system. We have asked a number of academics to develop a model for that.

How do you actually bring all of this work together and ultimately show that a political target is also going to be realized? A number of academics, in this case led by the joint research center IPTS in Seville, are working on that type of modeling. This is highly challenging and there is an example where you can 
go all the way from a practical partnership type of operation to things that people feel. Is their quality of life improved through innovation? For academic work that is necessary in order to provide evidence of the real benefits of investing in innovation. These are important decisions. Another example that I just briefly want to mention is that perhaps the academic work may be perceived as happening and staying only in the journals. How do you make it more relevant? Is it important that we do this kind of work, because we are contributing to, for example, a more functional economy or better international relationships. You have to make the step where you take a higher perspective of what your overall objective is, beyond that single objective of the individual company. That immediately pulls together different disciplines and makes easier the next step that you can explain why academic work is relevant for key decision makers, for those that are sitting on the money, for those that are talking about international relationships, for those that are closer or looser collaborations with China or Russia and the like. You have to take that perspective and I think that academics are very good at that. Having the debate about what is the purpose of what we actually do. This serious debate could well fit into editorials of, for example, Electronic Markets, or those kind of outlets, or in your conferences.

EM: Paul, thank you very much for the interview.

\section{Reference}

Timmers, P. (1998). Business models for electronic markets. Electronic Markets, 8(2), 3-8. 